\title{
DR. CLAUDI ESTEVA FABREGAT PUBLICACIONS 1947-2017
}

RECULL BIBLIOGRÀFIC PER BERTA ALCAÑIZ 



\section{Llibres}

1965 Función y Funcionalismo en las Ciencias Sociales.

Madrid, Consejo Superior de Investigaciones Científicas, 88 pp.

1972 Antropología y Filosofía.

Barcelona, Editorial Redondo S.A. 64 pp. ISBN 84-7159-083-2

1973 Antropología Industrial.

Barcelona, Editorial Planeta. Primera edició. 217 pp. ISBN 84-320-2405-8

1973 Cultura y Personalidad.

Barcelona. Editorial Redondo S.A. Primera Edició. 206 pp.

ISBN 84-7159-089-1

1975 Razas Humanasy Racismo.

Barcelona, Salvat Editores S.A. 140 pp. ISBN 84-345-7439-X

1978 Cultura, Sociedady Personalidad.

Barcelona, Promoció cultural S.A./Anthropos. Segona edició. 339 pp.

ISBN 84-7353-008-X

1981 Razas Humanas y Racismo.

Barcelona, Salvat Editores S.A. Segona edició. 140 pp.

ISBN 978-84-345-7781-7

1984 Antropología Industrial.

Barcelona, Anthropos. Editorial del Hombre. Segona edició revisada i aumentada. 396 pp. ISBN 84-85887-21-2

1984 Estado, Etnicidad y Biculturalismo.

Barcelona, Ediciones Península. 235 pp. ISBN 84-297-2140-1

1985 Campesinado y Colonialismo. El caso Andino

Sant Fost de Campsentelles, Ediciones Marzo 80, S.A.

ISBN 987-84-85725-28-1

1988 El Mestizaje en Iberoamérica.

Madrid, Editorial Alhambra. 401 pp. ISBN 84-205-1678-3

1989 La Corona Española y el Indio Americano.

Madrid, Asociación Francisco López de Gómara-Estudios i Ediciones S.A., 2 vols. Tom I: 232 pp.; Tom II: 211 pp.

ISBN 84-85861-07-8 (Obra Completa); ISBN 84-85861-06-X (Tom 1); ISBN 84-85861-05-1 (Tom 2)

1989 Antropologia Industriale.

Roma: Bulzoni Editore. XII + 260 pp. Introducció d'Aurelio Rígoli.

ISBN 88-7119-203-6

1992 El Imperio Azteca. Relatos del Nuevo Mundo

(Text i Presentació. Assessorament i Referència Històrica)

Barcelona, Editorial Planeta Agostini. ISBN 84-395-2049-2; ISBN 84-

395-2056-5 
1992 Indios y campesinos de los Andes.

Madrid. Ed. Akal.

ISBN 13: 978-84-7600-898-0; ISBN 10: 84-7600-898-8

1993 Cultura, Sociedady Personalidad.

Barcelona, Anthropos, Editorial del Hombre. Tercera edició ampliada. $463 \mathrm{pp}$.

ISBN 84-7658-415-6

1995 Mestizaje in Ibero-America.

Translated by John Wheat. 378 pp. Tucson \& London, The University of Arizona Press.

1995 Introducción a las Fuentes Etnográficas y la América Indígena.

Madrid, Fundación Mapfre América, Instituto Histórico Tavera. 124 pp. ISBN 84-7100-350-3

1996 Ciència i Etnociència a l'Antropologia.

Seminari Permanent, La Responsabilitat Social dels Científics.

Barcelona, Fundació Catalana per a la Recerca. 128 pp.

ISBN 84-89570-07-8

1998 Don Quijote y América

Universidad de Castilla la Mancha, Servicio de Publicaciones. 160 pp.

ISBN 84-89958-08-4

1998 Antropología y Antropólogos.

Entrevista per Joan Prat Carós i Ángel Martinez Hernáez.

Mèxic, Conaculta/UNAM. 158 pp.ISBN 970-18-1419-8.

2004 La identidad Catalana Contemporánea.

Mèxic, Fondo de Cultura Económica, 446 pp. ISBN 968 167404-9

2009 La influencia de México en el exilio español. Identidades en retrospectiva.

Mèxic, Editora de Gobierno del Estado de Veracruz, 137 pp.

ISBN 978-607-7527-15-2

2010 Formas Expresivas en Antropología.

Mèxic, Universidad Nacional Autónoma de México, Instituto de Investigaciones Antropológicas \& Zapopan, El Colegio de Jalisco. 264 + xi pp. ISBN UNAM: 978-607-02-1857-6; ISBN COLJAL: 978-607-7770-26-8 


\section{Assaig, articles, presentacions, i ressenyes crítiques}

1949 «Cultura y Método. Primer Part».

A: Presencia, no. 5-6:34-37. Mèxic.

1950 «Cultura y Método. Segona Part».

A: Presencia, no. 7: 41-48. Mèxic.

1950 Recensión a Abram Kardiner: «El individuo y su sociedad».

A: Boletin Bibliografico de Antropologia Americana, 1949, XII, Parte II: 139-141. Mèxic.

1950 Recensión a Clyde Kluckhohn; Henry A. Murray: «Personality. In nature, society and culture.

A: Boletin Bibliografico de Antropologia Americana, 1949, XII, Parte II: 143-146. Mèxic.

1951 Recensión a Ezra Park: «Race and culture».

A: Boletin Bibliografico de Antropologia Americana, 1950, XIII, Parte II: 141145. Mèxic.

1951 Recensión a George P. Murdock \& Clellan S. Ford.: «Outline of cultural materials».

A: Boletin Bibliografico de Antropologia Americana, 1950, XIII, Parte II: 139140. Mèxic.

1952 «En la Minoría del Futuro».

A: Prometeus, no. 2: 160-163. Mèxic.

1952 Recensión a Carey Mcwilliams: «Brothers under the skin».

A: Boletin Bibliografico de Antropologia Americana, 1951, XIV, Parte II: 28-31. Mèxic.

1952 Recensión a Michel Leiris: «Race et civilisation. La question raciale devant la science moderne».

A: Boletin Bibliografico de Antropologia Americana, 1951, XIV, Parte II: 26-28. Mèxic.

1952 Recensión a Otto Klineberg: «Race et Psychologie».

A: Boletin Bibliografico de Antropologia Americana, 1951, XIV, Parte II: 24-26. Mèxic.

1952 Recensión a Flora Bailey: «Some sex beliefs and practices in a navaho community».

A: Boletin Bibliografico de Antropologia Americana, 1951, XIV, Parte II: 103104. Mèxic.

1952 Comentario Crítico a Jeames Georges Frazer: «La Rama Dorada».

A: Prometeus, no. 5: 96-110. Mèxic.

1953 «Panorama de la Antropología Mexicana».

A: Cuadernos Hispanoamericanos, no. 37:14 pp. Madrid.

1954 Recensión a Eduard Sapir: «El Lenguaje y sus problemas».

A: Cuadernos Americanos XIII, 6: 142-145. Mèxic. 
1954 Recensión a Ferdinand Zweig: «El pensamiento económico y su perspectiva histórica».

A: El Trimestre Económico XXI, 3:367-369. Mèxic.

1954 Recensión a Melville J. Herskovits: «Antropología Económica».

A: El Trimestre Económico XXI, 2: 227-231. Mèxic.

1954 Recensión a Géza Röheim: «Psychoanalysis and Anthropology».

A: Boletin Bibliografico de Antropologia Americana, 1952-1953, XV-XVI, Parte II: 196-201. Mèxic.

1954 Recensión a John W. M. Whiting \& Irvin L. Child: «Child training and Personality».

A: Boletin Bibliografico de Antropologia Americana, 1952-1953, XV-XVI, Parte II: 212-215. Mèxic.

1954 Recensión a Margaret Mead: «Educación y Cultura».

A: Boletin Bibliografico de Antropologia Americana, 1952-1953, XV-XVI, Parte II: 186-189. Mèxic.

1954 Recensión a Erich Fromm: «Ética y Psicoanálisis».

A: Boletin Bibliografico de Antropologia Americana, 1952-1953, XV-XVI, Parte II: 173-177. Mèxic.

1954 Recensión a VARIOS: «Culture and Personality. Proceedings of an Interdisciplinary Conference».

A: Boletin Bibliografico de Antropologia Americana, 1952-1953, XV-XVI, Parte II: 164-171. Mèxic.

1954 Recensión a David Bidney: «Theoretical Anthropology».

A: Boletin Bibliografico de Antropologia Americana, 1952-1953, XV-XVI, Parte II: 145-148. Mèxic.

1954 «Bidney y el Normatismo Cultural».

A: Ciencias Sociales, no. 29: 207-215. Washington, D.F.

1954 «Cañas. Intérprete de México».

A: Revista de Economía Hispano-Mexicana, Septiembre: 28-30. Mèxic.

1955 «Cañas. Una antropología escultórica del indio mexicano.»

A: Indice de Artes y Letras, no.78, p. 9-10. Madrid.

1955 «The Concept of Pattern and the Theory of the Cultural Personality».

A: Psychiatric Research Reports, vol. 2: 171-176. Washington, D.C.

1955 «La "Antropología Social" de Siegfried Ferdinand Nadel».

A: Boletin Bibliografico de Antropologia Americana, vol. VXIII, parte segunda: 153-164, Mèxic.

1955 «La "Antropología Social" de Siegfried Ferdinand Nadel». A: Cuadernos Americanos, septiembre-octubre pp. 211-213. Mèxic.

1955 «Tiempo de México: Fuerza y Presencia del Mestizaje».

A: Revista de Economía Hispano-Mexicana, Enero: 14-15. Mèxic. 
1955 Recensión crítica a Gonzalo Aguirre Beltrán.

A: Boletin Bibliografico de Antropologia Americana, Parte II: 181-186. Mèxic.

1955 Recensión a «II Congreso Interamericano de Psicología».

A: Boletin Bibliografico de Antropologia Americana, XVII, Parte I: 43-53. Mèxic.

1955 Recensión a Martin Buber: «Caminos de Utopía».

A: Universidad de México, X, 2: 6-7. Mèxic.

1955 Recensión a H. Frankfort; H. A. Frankfort; J. A. Wilson; T. Jacobsen; \& W. Irwin: «El pensamiento prefilosófico».

A: Universidad de México, IX, 10.11: 4 y 14. Mèxic.

1955 Recensión a Ramón Rubin: «La bruma lo vuelve azul».

A: Cuadernos Americanos, XIV, 2: 293-295. Mèxic.

1955 Recensión a Siegfried F. Nadel: «Fundamentos de Antropología Social».

A: Cuadernos Americanos, XIV, 5: 211-213. Mèxic.

1955 Recensión a Vere Gordon Childe: «Los orígenes de la civilización».

A: Cuadernos Americanos, XIV, 1: 210-213. Mèxic.

1956 «La investigación del átomo».

A: Índice de Artes y Letras, no.95-96, p.30. Madrid.

1956 «Ser o no ser todavía. Municipio y responsabilidad humana. Hispanoamérica o la americanización de lo europeo». (Firmado con el seudónimo Iberico)

A: Índice de Artes y Letras, no. 94, pp. 6-7. Madrid.

1956 «Los aztecas. Un estilo de vida».

A: Índice de Artes y Letras, no.93, pp. 8-9. Madrid.

1956 «Interpretación de México».

A: Cuadernos Hispanoamericanos, no. 83: 174-182. Madrid.

1956 «Unamuno. La Literatura Hispanoamericana».

A: Indice de Artes y Letras, no. 95-96:33. Madrid.

1956 «¿Ser o no Ser Todavía?. Municipio y Responsabilidad Humana. Hispanoamérica o la Americanización de lo Americano».

A: Indice de Artes y letras, no. 94: 6-7. Madrid.

1956 «Los Aztecas».

A: Indice de Artes y Letras, no. 93: 8-9. Madrid.

1956 «Hacia una Antropología Industrial».

A: Comercio Exterior, Agosto:382-385. Mèxic.

1956 «La Antropología en Hispanoamérica».

A: Humanismo, no. 40: 74-82. Mèxic.

1956 «Existencialisme i Crisi Humana».

A: Pont Blau, no. 39: 18-23. Mèxic.

1956 Recensión a Ilse Schwidetzky: «Etnobiología».

A: Cuadernos Americanos, XV, 2: 129-133. 
1956 Recensión a Friedrich Kainz: «La estética fenomenológica».

A: Universidad de México, X, 5:27-28. Mèxic.

1956 Recensión a Juan Rulfo: «El llano en llamas».

A: Índice Artes y Letras, núm.92, p. 21. Madrid.

1957 «La educación y la crisis de la unidad humana». (Firmado con el seudónimo Ibericus).

A: Indice de Artes y Letras, no. 108, pp. 20-21. Madrid.

1957 «No estamos solos». (Firmado con el seudónimo Ibericus).

A: Indice de Artes y Letras, no. 107, pp. 20-21. Madrid.

1957 «Algunos Problemas de Antropología Industrial».

A: Comercio Exterior, Enero: 27-30. Mèxic.

1957 «El Indio como Problema».

A: Revista de Estudios Politicos, no. 95: 211-239. Madrid.

1957 «Sobre la Teoría y los Métodos de la Antropología Social».

A: Revista Internacional de Sociología, no. 59. 411-436. Madrid.

1957 «La Antropología Contemporánea».

A: Revista de Estudios Políticos, no. 91: 95-125. Madrid.

1957 «La Educación y la Crisis de la Unidad Humana».

A: Indice de Artes y Letras, no. 108: 20-21. Madrid.

1957 «No Estamos Solos».

A: Indice de Artes y Letras, no. 107: 20-21. Madrid.

1957 «Naturaleza y Razón en Hispanoamérica. El Indigenismo Peruano».

A: Indice de Artes y Letras, no. 102: 22. Madrid.

1957 «Razón y Entusiasmo de Bolivia».

A: Indice de Artes y Letras, no. 98: 10. Madrid.

1957 «El arte en la crisis de la libertad humana. Bases para una filosofía de lo americano». (Firmado con el seudónimo Ibericus).

A: Indice de Artes y Letras, no. 104, p. 21. Madrid.

1957 «La técnica y el ser humano». (Firmado con el seudónimo Ibericus).

A: Índice de Artes y Letras, no.103, p. 19. Madrid.

1957 «Naturaleza y razón en Hispanoamérica. El indigenismo peruano». (Firmado con el seudónimo Ibericus).

A: Indice de Artes y Letras, no.102, p. 22. Madrid.

1957 «Pancho Villa. Freud». (Firmado con el seudónimo Iberico)

A: Indice de Artes y Letras, no.101, p. 22. Madrid.

1957 «Lydia Nogales. Razón y entusiasmo de Bolivia». (Firmado con el seudónimo Ibericus).

A: Índice de Artes y Letras, no. 98, p. 10. Madrid.

1957 «Saber mirar. ¿Adonde va la cultura hispanoamericana? Irving A. Leonard». (Firmado con el seudónimo Iberico).

A: Índice de Artes y Letras, no. 97, p. 29. Madrid. 
1957 «Recensión a Josefina Zoraida Vazquez Vera: El indio americano y su circunstancia en la obra de Oviedo».

A: Revista de Indias 67: 155-157.

1958 «Horario del Comercio de Madrid».

A: Comercio, Octubre: 891-893. Madrid.

1958 «Tragedia y Paradoja del Intelectual».

A: Indice de Artes y Letras, no. 113: 22-23. Madrid.

1958 «¿Hacia Dónde Va la Civilización Industrial?».

A: Indice de Artes y Letras, no. 112: 22. Madrid.

1958 «Europa en la Inteligencia Mexicana».

A: Indice de Artes y Letras, no. 110: 21. Madrid.

1958 «La Crisis Universitaria».

A: Indice de Artes y Letras, no. 109: 20. Madrid.

1958 «Tragedia y paradoja del intelectual. (Firmado con el seudónimo Ibericus)».

A: Índice de Artes y Letras, no. 113, pp. 22-23. Madrid.

1958 «¿Hacia dónde va la civilización industrial?» (Firmado con el seudónimo Ibericus).

A: Índice de Artes y Letras, no. 112, p. 22. Madrid.

1958 «Europa en la inteligencia mexicana». (Firmado con el seudónimo Ibericus).

A: Indice de Artes y Letras, no. 110, p. 21. Madrid.

1958 «La crisis universitaria. Energía social y tiempo institucional. Atracción actual de la Universidad». (Firmado con el seudónimo Ibericus).

A: Índice de Artes y Letras, no. 109, p. 20. Madrid.

1958 Recensión a Laurette Séjourné: «Pensamiento y religión en el Mèxic Antiguo».

A: Revista Interamericana de Bibliografia, 1: 69-70. Washington, D.C.

1958 Recensión a Laurette Séjourné: «Pensamiento y religión en el Mèxic Antiguo».

A: Arbor, 156: 304-306. Madrid.

1958 Recensión a Juan Comas: «Manual de Antropologia Física».

A: Arbor 155:323-324. Madrid.

1958 Recensión a Julio Caro Baroja: «Razas, Pueblos y Linajes».

A: Arbor 153-154. 162-164. Madrid.

1958 Recensión a Leonard Cottrell: «The anvil of civilisation».

A: Arbor, 153-154: 161-162. Madrid.

1958 Recensión a Carleton S. Coon: «The history of man».

A: Arbor, 153-154: 159-161. Madrid.

1959 «Muerte de Alfonso Reyes».

A: Indice de Artes y Letras, no. 132, p. 25. Madrid. 
1959 «Letras Hispánicas. Estudios, Esquemas».

A: Índice de Artes y Letras, no. 121, p. 25. Madrid.

1959 «Sobre el Método de la Arqueología».

A: Revista de Indias, no. 75: 89-106. Madrid.

1959 «La Coyuntura Iberoamerican».

A: Horizontes, no. 9: 10. Mèxic.

1959 «El Desarraigo».

A: Horizontes, no. 6:12-13. Mèxic.

1959 Recensión a Edmundo O'Gorman: «La invención de América».

A: Revista de Indias, 76: 299-300. Madrid.

1959 Recensión a Herbert Wendt: «Tras las huellas de Adán».

A: Arbor, 157: 151-152. Madrid.

1959 Recensión a Ruth Moore: «Hombre, tiempo y fósiles».

A: Arbor, 157: 150-151. Madrid.

1959 Recensión a E. Adamson Hoebel: «Man in the primitive world».

A: Arbor, 157: 148-152. Madrid.

1959 Recensión a Martín Almagro: «Origen y formación del pueblo hispano».

A: Índice Artes y Letras, $\mathrm{n}^{\mathrm{a}}$ 120, p. 30 . Madrid.

1960 «Rituales de Nacimiento entre los Aztecas de México-Tenochtitlan».

A: Akten des 34. Internationalen Amerikanistenkongresses, Wien, Austria, pp. 678-687.

1960 «América como Unidad y Sistema de una Idea».

A: Jornal, no. 90: 601-602. Madrid.

1960 «El Poblamiento Antiguo de América».

A: Comercio, no. 114:45-49. Madrid.

1960 «La Máquina y la Deshumanización del Trabajo».

A: Cuadernos de Política Social, no. 47:43-77. Madrid.

1960 «Industrialización e Integración Social».

A: Cámara Oficial de Comercio, 36 pp. Madrid

1960 «Industrialización e Integración Social».

A: Comercio, Abril: 29-36 y 61. Madrid.

1960 «Sociodinámica del Capitalismo Contemporáneo».

A: Cuadernos de Centro de Estudios, no. 14: 200-221. Madrid.

1960 «Las Relaciones Humanas en el Marco del Trabajo y el Sindicalismo».

A: Jornal, no. 81:3-8. Madrid.

1960 «Marañón. Sentido de una vida».

A: Horizontes, no. 13:5-6. Mèxic.

1960 «El Mestizaje Iberoamericano».

A: Horizontes, no. 13: 5-6. Mèxic.

1960 «La Crisis del Sentimiento de Comunidad».

A: Horizontes, no. 10: 9. Mèxic. 
1960 «El Método Funcionalista en el Estudio de la Aculturación».

A: Actes du VIe. Congrès International des Sciences Anthropologiques et Ethnologiques, (París, 1960), Tom. II, volumen 2: 583-587. París.

1960 «La Sociología en nuestro tiempo».

A: Indice de Artes y Letras, no. 141, p. 24. Madrid.

1960 «El mundo y la civilización en los siglos Xvi y xvi».

A: Indice de Artes y Letras, no. 135, p. 24. Madrid.

1960 Recensión a Mauricio Swadesh: «Mapas de clasificación lingüística de Mèxic y las Américas».

A: Boletin Americanistas II, 4: 65-66. Barcelona.

1960 Recensión a Gonzalo Aguirre Beltrán: «Cuijla».

A: Revista de Indias, 79: 132-133. Madrid.

1960 Recensión A Jesús Anaya Topete: «Atlas Mexicano De La Conquista».

A: Revista de Indias, 79: 127. Madrid.

1960 Recensión a R. P. Bergounioux: «La Prehistoria y sus problemas».

A: Arbor, 180: 147-149. Madrid.

1960 Recensión a Martin Almagro Basch: «Introducción al estudio de la Prehistoria».

A: Arbor, 180: 145-146. Madrid.

1961 «El Carácter Nacional Azteca y la Educación Juvenil».

A: Revista de Indias, 84: 225-254. Madrid.

1961 «Estructura Etnica y Social de Iberoamérica».

A: Centro Europeo de Documentación e Información. Madrid, 11 pp.

1961 «El Indigenismo en la Política Hispanoamericana».

A: Revista de Política Internacional, no. 56-57: 49-63. Madrid.

1961 «Una Teoría de la Sociedad Oriental».

A: Comercio, no. 128:10-19. Madrid.

1961 «El Krausismo en la Ideología Española».

A: Horizontes, no. 20:22-23 y no. 21:22-23. Mèxic.

1961 Recensión a Leonhard Adam \& Hermann Trimborn (Eds.): «Lehrbuch der Völkerkunde».

A: Revista de Indias, 84: 353-354. Madrid.

1961 Recensión a Sherburne F. Cook: Santa María Ixcatlán. «Habitat, Population, Subsistence».

A: Revista de Indias, 83: 189-190. Madrid.

1961 Recensión a Paul Rivet: «Los orígenes del hombre americano».

A: Arbor, 191: 170-171. Madrid.

1961 Recensión a D. F. Pocock: «Social Anthropology».

London, Sheed \& Ward.

A: Revista Internacional de Sociología, $\mathrm{N}^{\circ} 74$. Madrid. 
1961 Recensión a Martin Almagro Basch: «Prehistoria. Tom. I, Manual de Historia Universal».

A: Arbor, 186: 136-140. Madrid.

1961 Recensión a Martin Almagro: «Prehistoria».

A: Índice Artes y Letras, $n^{a}$ 145, pp. 23-24. Madrid.

1961 Recensión a Juan Comas: «Pigmeos en América?»

A: Revista de Indias, 84: 356-357. Madrid.

1961 Recensión a Juan Comas: «El índice cnémico en tibias prehispánicas y modernas del Valle de México».

A: Revista de Indias, 84: 356. Madrid.

1961 Recensión a Santiago Genovés Tarazaga: «Diferencias sexuales en el hueso coxal».

A: Revista de Indias, 84:360-361. Madrid.

1961 Recensión a Laurette Séjourné: «Un palacio en la ciudad de los dioses». A: Revista de Indias, 84:368-369. Madrid.

1962 «Contexto Cultural del Urbanismo».

A: In, no. 8: 58-63. Madrid.

1962 «Rituales de Nacimiento entre los Aztecas de México-Tenochtitlan».

A: Akten des 34 Internationalen Amerikanisten-Kongresses (Wien, 1960), pp. 678-687. Viena.

1962 «Cultura, Sociedad y Salud Mental».

A: Revista de la Universidad de Madrid, no. 37:287-332. Madrid.

1962 «Desarrollo Social y Planificación Social».

A: Boletín de Estudios Económicos, no. 57: 525-562. Bilbao.

1962 «Una opinión española sobre el 'Juárez' de Pere Foix».

A: Índice de Artes y Letras, Madrid i a Mèxic En la Cultura, 1962, núm. 692, p. 8.

1962 Recensión a Pedro Bosch-Gimpera: «El Problema Indoeuropeo».

A: Revista de Indias, 1962, 89-90: 532-534. Madrid; i a UNAM, Mèxic 1960.

1962 Recensión a Walter Krickeberg, Herman Trimborn, Werner Múller y Otto Zerries: «Die Religionen des Alten Amerika».

Stuttgart, W. Kohlhammer Verlag, 1961.

A: Revista de Indias, 1962: 571-572. Madrid.

1962 Recensión a John Collier: «Los indios de las Américas».

A: Cuadernos Hispanoamericanos, 149: 308-311. Madrid.

1962 Recensión a Manuel Ballesteros Gaibrois y Julia Ulloa Sanchez: «Indigenismo americano».

A: Cuadernos Hispanoamericanos, 148: 131-133. Madrid.

1962 Recensión a Alden J. Mason: «Las antiguas culturas del Perú». A: Arbor, 203: 141-142. Madrid.

1962 Recensión a Manuel Ballesteros Gaibrois \& Julia Ulloa Sanchez: «Indigenismo americano».

A: Revista de Estudios Politicos, 123: 391. Madrid. 
1962 Recensión a Gilberto Freyre: «O luso e o trópico».

A: Revista de Estudios Politicos, 121: 301-302. Madrid.

1962 Recensión a José Ortega Y Gasset: «Meditación de Europa».

A: Revista de Estudios Politicos, 121: 312-313. Madrid.

1962 Recensión a Walter Krickeberg, Hermann Müller \& Otto Zerries: «Die religionen des Alten Amerika».

A: Revista de Indias, 89-90: 571-572. Madrid.

1962 Recensión a Walter Krickeberg: «Las antiguas culturas mexicanas».

A: Arbor, 193: 108-11ㅇ. Madrid.

1962 Recensión a Augusto Panyella y Otros: «Razas Humanas».

A: Arbor, 192: 132-133. Madrid.

1962 Recensión a Wheeler Mortimer: «Arqueología de campo».

A: Arbor, 192:131-132. Madrid.

1962 Recensión a Edmundo O'Gorman: «La invención de América».

A: El Mercurio, 8 de Abril, Santiago de Chile, 8 de Abril.

1963 «Cultura y Personalidad».

A: Revista de Psicología General y Aplicada, no. 66-67:163-224. Madrid.

1963 «La Automatización como Problema».

A: Horizontes, no. 31: 29-30. Mèxic.

1963 Recensión a Samuel Marti: «Canto, danza y música precortesianas».

A: Cuadernos Hispanoamericanos, 157: 144-146. Madrid.

1963 Recensión a Paul Westheim: «Arte antiguo de México».

A: Arbor, 215: 158-160. Madrid.

1963 Recensión a Raymond A. Dart \& Dennis Craig: «Aventuras con el eslabón perdido».

A: Arbor, 213-214: 150-151. Madrid.

1963 Recensión a Woodrow Borah \& Sherburne F. Cook: «The aboriginal population of Central Mexico on the eve of the Spanish Conquest».

A: Revista de Indias, 93-94: 535-536. Madrid.

1963 Recensión a Joseph de Acosta: «Historia natural y moral de las Indias». A: Revista de Indias, 93-94: 533-534. Madrid.

1963 Recensión a Rafel Girard: «Indios selváticos de la Amazonía peruana». A: Revista de Indias, 91-92: 326-327. Madrid.

1963 Recensión a Inca Garcilaso de La Vega: «La Florida del Inca. Historia del Adelantado Hernando de Soto».

A: Revista de Indias, 91-92:328. Madrid.

1963 Recensión a Mino Vianello: «Thorstein Veblen».

A: Anales de Economia, $2^{\text {a }}$ Epoca, 2: 455-459. Madrid.

1963 Recensión a Calixta Guiteras-Holmes: «Perils of the soul. The world view of a Tzotzil indian».

A: Cuadernos Hispanoamericanos, p. 191-194, octubre'63. Madrid. 
1964 «El Mestizaje en Iberoamerica».

A: Revista de Indias, no. 95-96: 279-354. Madrid.

1964 «Antropología y Prehistoria».

A: Enciclopedia Metódica Larousse, pp. 190-197. Buenos Aires.

1964 "Algunos Caracteres del Sistema de Propiedad "Fang"».

A: Revista de Trabajo, no. 5: 119-154. Madrid.

1964 «El Indigenismo en Iberoamérica».

A: Revista Española de Indigenismo, Enero: 3-4. Madrid.

1964 «La Integración como Problema de Nuestra Epoca».

A: Horizontes, no. 37: 12-13. Mèxic.

1964 «Desarrollo Económico y ¿Qué más?».

A: Horizontes, no. 35-36: 23-24. Mèxic.

1965 «El Acto Intelectual».

A: Horizontes, no. 22, Mèxic.

1965 «Aculturación y Mestizaje en Iberoamérica. Algunos Problemas Metodológicos».

A: Revista de Indias, no. 97-98: 445-472. Madrid.

1965 «Preguntas y respuestas sobre el ser humano, M. Buber».

A: Revista Mexicana de Cultura, núm. 958, p. 6.

1965 Recensión a «Actas y Memorias: XXXV Congreso Internacional de Americanistas».

A: Anales de Antropologia, II: 208-214. Mèxic.

1965 Recensión a Juan Comas: «La Antropología Social Aplicada en México». A: Anales de Antropologia, II: 200-203. Mèxic.

1965 Recensión a Luis Pericot Garcia: «América Indígena, Tom. I». A: Revista de Indias, 99-100: 280-282. Madrid.

1965 Recensión a Alberto Ruz Lhuillier (Ed.): «Estudios de cultura maya, Vol. II«, Mèxic, UNAM, 1962, 358 pp.

A: Boletín Bibliográfico de Antropología Americana. Instituto Panamericano de Geografía e Historia. Vol. XXIII-XXV, 1960-1962, parte 2, pp. 41-42. Mèxic.

1965 Recensión a María Isaura Pereira de Queiroz: «La "guerre sainte" au Brasil: Le mouvement messianique du "Contestado"». Sao Paulo, Universidade de Sao Paulo. Faculdade de Filosofía, Ciencias e Letras, 1957, 299 pp.

A: Boletín Bibliográfico de Antropología Americana. Instituto Panamericano de Geografía e Historia. VOL. XXIII-XXV, 1960-1962, parte 2, pp. 80-82. Mèxic.

1965 Recensión a José María Vázquez O.P.: Pucallpa. «Estudio socio-religioso de una ciudad del Perú». Madrid, Editorial O.P.E., 1962.

A: Boletín Bibliográfico de Antropología Americana, Instituto Panamericano de Geografía e Historia. VOL. XXIII-XXV, 1960-1962, parte 2, p. 97. Mèxic. 
1966 «iPobreza o Desorganización Social?».

A: Indice de Artes y Letras, no. 213: 41-42. Madrid.

1966 «El Proceso de Mestizaje en América».

A: Aconcagua, no. 2: 156-173. Madrid.

1966 «Problemática y Orientación del V Congreso Indigenista Interamericano». A: Revista Española de Indigenismo, no. 6: 5-9. Madrid.

1966 Recensión a Claude Levi-Strauss: «Structural Anthropology». A: Anales de Antropologia, III: 303-306. Mèxic.

1966 Recensión a I. C. Jarvie: «The revolution in Anthropology». A: Anales de Antropologia, III:300-303. Mèxic.

1966 Recensión a «American Association Of Physical Anthropologists Yearbook of Physical Anthropology», 1963.

A: Revista de Indias, 105-106: 546. Madrid.

1966 Recensión a Oscar Schmieder: «Geografia de América». A: Revista de Indias, 105-106: 543-544. Madrid.

1966 Recensión a Sylvanus G. Morley: «La civilización maya». A: Revista de Indias, 105-106: 542. Madrid.

1966 Recensión a Rafael Girard: «Los mayas. Su historia, sus vinculaciones continentales».

A: Revista de Indias, 105-106: 519-522. Madrid.

1966 Recensión a José Alcina Franch: «Manual de Arqueologia Americana». A: Revista de Indias, 105-106: 515-516. Madrid.

1966 Recensión a Daryll C. Forde: «Habitat, Economia y Sociedad».

A: Revista Internacional de Sociologia, 95-96: 444-445. Madrid; i a Estudios Geograficos, XXVII, 105: 666-667. Madrid.

1966 Recensión a Eduard Seler: «Codice Borgia».

A: Indice de Artes Y Letras, 209: 44-45. Madrid.

1967 «Informe Sobre la Situación de las Ciencias Antropológicas en España». En:"Anuario Indigenista", vol. XXVII: 111-114. Mèxic.

1967 «La Etnopsicología y el Estudio de Valores».

A: Revista de Psicología General y Aplicada, no. 86-87: 107-141. Madrid.

1967 «Lo Africano en los Países Americanos».

A: Horizontes, Marzo: 25-27. Mèxic.

1967 Recensión a Walter Goldschmidt: «Comparative functionalism». A: Anales de Antropologia, IV: 263-266. Mèxic.

1967 Recensión a Ugo Bianchi: «Storia dell'Etnologia». A: Anales de Antropologia, IV:256-258. Mèxic.

1968 «El Mestizaje en América».

A: Las Raices de América, Editor, J.M. Gómez Tabanera;pp. 279-314. Madrid, Instituto Español de Antropología Aplicada 
1968 «Ethics of Authority in the Mexican Family».

A: Proceedings of the VIIIth. International Congress of Anthropological and Ethnological Sciences (1968), Tokyo-Kyoto, vol. II: 358-359.

1968 Recensión a Garci Diez de San Miguel: «Visita hecha a la Provincia de Chucuito por ... en el año 1567».

A: Revista de Indias, 113-114: 501-502. Madrid.

1969 «La Revolución Mexicana y Emiliano Zapata».

A: Urogallo, Diciembre: 66-68. Madrid.

1969 «El Etnólogo como Conservador de Museo».

A: Pyrenae, no. 5: 59-84. Barcelona.

1969 «Familia y Matrimonio en México: El Patrón Cultural».

A: Revista de Indias, no. 115-118: 173-278. Madrid.

1969 «La Etnología Española y sus Problemas».

A: Actas del I Congreso de Artes y Costumbres Populares, Zaragoza, Institución "Fernando el Católico", pp. 1-40.

1969 «Sobre el Método y los Problemas de la Antropología Estructural».

A: Convivium, no. 30:3-54. Barcelona.

1970 «Algunas Funciones y Relaciones del Compadrazgo y del Matrimonio en Chinchero, Cuzco (Perú)».

A: Universitas, no. 6-7: 55-90. Salvador, Bahia (Brasil).

1970 «Medicina Tradicional, Curanderismo y Brujería en Chinchero (Perú)».

A: Anuario de Estudios Americanos, tom. XXVII: 19-60. Sevilla.

1970 «Un Mercado en Chinchero, Cuzco (Perú)».

A: Anuario Indigenista, no. XXX: 213-254. Mèxic.

1971 «Para una Teoría de la Aculturación en el Alto Aragón».

A: Ethnica, 2: 9-75. Barcelona.

1971 «El Circummediterráneo y sus Relaciones con la América Prehispánica: ¿Difusión o Paralelismo?».

A: Anuario de Estudios Atlánticos, 17: 151-197. Madrid-Las Palmas.

1971 «Actividades Antropológicas en Barcelona: 1970».

A: Revista Española de Antropología Americana , 6: 471-476. Madrid.

1971 «Los Usos de la Coca en Chinchero, Cuzco (Perú).»

A: Munibe, vol. XXIII, no. 4: 429-443. San Sebastián.

1971 «Antropología Social».

A: Enciclopedia Proliber, pp. 432-437. Madrid, Editorial Proliber

1971 «Algunos Caracteres del Sistema de Propiedad "Fang"».

A: Ethnica, 1: 31-59. Barcelona.

1971 «Antecedentes y Propósitos. Introducción al Número 1 de Ethnica».

A: Ethnica, 1: 9-11. Barcelona.

1971 «Sobre el Método y los Problemas de la Antropología Estructural».

A: Sociología Española de los años setenta, pp. 593-645. Madrid, Confederación Española de Cajas de Ahorros. 
1971 «Actividades antropológicas en Barcelona: 1970». Revista Española de Antropologia Americana, 6: 471-476. Madrid.

1972 «La Población de Chinchero (Cuzco, Perú) en el Siglo xviI».

A: Publicaciones de la Comisión Nacional del Sesquicentenario de la Independencia del Perú, tom. III: 318-340. Lima.

1972 «Ayni, Minka y Faena en Chinchero, Cuzco (Perú)».

A: Revista Española de Antropología Americana, vol. 7 no. 2: 309-407. Madrid.

1972 «Rol y Estatus Según el Sexo en México».

A: Verhandlungen des XXXVIII Internationalen Amerikanistenkongresses, vol. IV: 337-340. München.

1972 «L'Estude du Village en Espagne».

A: Ethnologia Europaea, vol. VI, no. 1: 74-85. Gòttingen.

1972 «Antropología y Filosofía».

A: Ethnica, 3: 53-83. Barcelona.

1973 «La Población Mundial».

A: "La Población Mundial", pp. 5-8. Barcelona, Promoción Cultural.

1973 «Inmigración, Etnicidad y Relaciones Interétnicas en Barcelona».

A: Ethnica, 6: 73-129. Barcelona.

1973 «Contribucions a una Teoria del Bilingüisme».

A: In Memoriam Carles Riba, pp. 165-183. Barcelona, Editorial Ariel.

1973 «Suggesting a Discussion About Relations Between Anthropology and Philosophy».

A: Current Anthropology, vol. 14, no. 4:335. Chicago.

1973 «Aculturación y Urbanización de Inmigrados en Barcelona. ¿Cuestión de Etnia o Cuestión de Clase?».

A: Ethnica, 5: 135-189. Barcelona.

1973 «Las Culturas Indígenas del Brasil y la Conquista y Colonización Portuguesas: Condicionamientos Culturales y Ecológicos del Indígena Brasileño».

A: El Tratado de Tordesillas y su Proyección, tom. I: 329-344. Valladolid, Primer Coloquio Luso-Español de Historia de Ultramar. Valladolid, Universidad de Valladolid.

1973 «El Derecho en los Pueblos Primitivos».

A: Universitas, no. 116: 211-219. Barcelona, Salvat Editores.

1973 «La Economía Primitiva».

A: Universitas, no. 113: 155-160. Barcelona, Salvat Editores.

1973 «El Mito en la Literatura Oral».

A: Universitas, no. 110: 95-110. Barcelona, Salvat Editores.

1973 «Funciones Sociales del Parentesco».

A: Universitas, no. 106: 9-15. Barcelona, Salvat Editores.

1973 «Magia».

A: Universitas, no. 105: 281-285. Barcelona, Salvat Editores. 
1973 «El Animismo».

A: Universitas, no. 102: 231-237. Barcelona, Salvat Editores.

1973 «El Totemismo».

A: Universitas, no. 98: 145-151. Barcelona, Salvat Editores.

1973 «Un Enfoque Estructural del Mito Según Lévi-Strauss: L'Homme Nu. Una Evaluación y un Resumen. The Structure of Myths According to Lévi-Strauss: L'homme Nu. An Evaluation and Summary».

A: The Human Context, vol. V. no. 231-237. London.

1973 Recensión Crítica a Gonzalo Aguirre Beltrán: «Instituciones Indígenas del Mèxic Actual».

A: Homenaje a G. Aguirre Beltrán, Tom. III, pp. 91-97. Instituto Indigenista Interamericano, Mèxic, D.F. 1973. También en 1955, Boletín Bibliográfico de Antropología Americana, 2a. Parte, pp. 181-186. Mèxic, D.F

1973 Recensión a «Darwinian Psychological Anthropology. A Biosocial Approach».

A: Current Anthropology, vol. 14. no. 4:379. Chicago.

1974 «Población y mestizaje en las ciudades de Iberoamérica: siglo xviII.

A: Revista de Indias, número 131-138

1974 «Aculturación Lingüistica de Inmigrados en Barcelona».

A: Ethnica, no. 8: 73-120. Barcelona.

1974 «Cambio Sociocultural en el Alto Aragón».

A: II Congreso Nacional de Artes y Costumbres Populares, pp. 1-8. Zaragoza, Institución "Fernando el Católico".

1974 «Inmigración y Confirmación Etnica en Barcelona».

A: In Memoriam Antonio Jorge Días, vol. II: 135-162. Lisboa, Portugal.

1974 «La Guerra y el canibalismo».

A: Universitas, 119: 271-275. Barcelona, Salvat Editores.

1975 «En Torno a los Congresos Internacionales de Americanistas».

A: Ethnica, No. 9: 143-149. Barcelona.

1975 «La Antropología Aplicada y Su Problemática».

A: Primera Reunión de Antropólogos Españoles, pp. 253-321. Sevilla, Universidad de Sevilla.

1975 «Población y Mestizaje en las Ciudades de Iberoamérica».

A: Estudios Sobre la Ciudad Iberoamericana, pp. 551-604. Coordinador. Francisco de Solano. Madrid, Instituto Gonzalo Fernández de Oviedo, Consejo Superior de Investigaciones Científicas (CSIC).

1975 «Etnia, Etnicidad y Relaciones Interétnicas».

A: Revista de la Universidad Complutense de Madrid, vol. XXIV, No. 97:37-77.

1975 «Les Relacions Interètniques. El Cas de Barcelona».

A: Perspectiva Social, No. 5: 41-68. Barcelona. 
1975 «Antropología Cultural».

A: Historia Universal de la Medicina, tom. 7, pp. 102-103. Pedro Laín Entralgo (dir.). Barcelona, Salvat Editores.

1975 «Ethnicity, Social Class and Acculturation of Immigrants in Barcelona».

A: Ethnología Europaea, vol. VIII, no. 1: 23-43. Göttingen.

1975 «Culturología».

A: Diccionario de Ciencias Sociales, pp. 615-617. Madrid, Instituto de Estudios Políticos.

1975 «Area Cultural».

A: Diccionario de Ciencias Sociales, pp. 168-169. Madrid, Instituto de Estudios Políticos.

1976 «Elementos para una Fundamentación Antropológica del Bilingüismo». A: Ethnica, 11, pp. 67-134. Barcelona.

1976 «Consciencia Etnica y Consciencia de Clase: El Caso de Cataluña». A: Estudios Regionales, pp. 385-390. Madrid, Instituto Nacional de Prospectiva y Desarrollo Económico.

1976 «Inmigration and Ethnic Confirmation in Barcelona».

A: Aceves, Hansen y Levitas (Eds.), pp. 14-21. New York, Queens College Press.

1976 «Sistema Cultural».

A: Diccionario de Ciencias Sociales, vol. II, pp. 872-874. Madrid, Instituto de Estudios Políticos.

1976 «Patrón Cultural».

A: Diccionario de Ciencias Sociales, vol. II, pp. 453-454. Madrid, Instituto de Estudios Políticos.

1976 «ulturkreise».

A: Diccionario de Ciencias Sociales, vol. II, pp. 43-45. Madrid, Instituto de Estudios Políticos.

1976 «The Changing Work Ethic in the Alto Aragón».

A: Aceves $y$ Douglas (Eds.), The Changing Face of Rural Spain, pp. 163-172. Cambridge, Mass. Scheckman Publishing Co.

1976 «Recensión a Stanley BRANDES: Migration, Kinship and Comunity.

New York, Academic Press.

A: Ethnica, 12: 175-178. Barcelona.

1977 «El Primer Congreso Español de Antropología».

A: Diario de Barcelona, 6 de Abril, p. 9. Barcelona.

1977 «Aculturació Lingüistica d'Immigrats a Barcelona».

A: Treballs de Sociolingüistica Catalana, vol. I, pp. 81-115. València, Llibreria Tres i Quatre. 
1977 «El Mestizaje en el Virreinato del Perú: Finales del Siglo xvi y Comienzos del xviII».

A: Rivera Dorado, Miguel (ed.), Antropología de España y América, pp. 265279. Madrid, Dosbe.

1977 «Recensión a Juan Comas (ed.), In Memoriam Pedro Bosch Gimpera: 1891-1974».

En : Anales de Antropología, vol. XIV, pp. 474-476. Mèxic, UNAM.

1978 «El Cambio de la Etica Laboral en el Alto Aragón».

A: William A. Douglass \& Joseph B. Aceves (eds.), Los Aspectos Cambiantes de la España Rural. Barcelona, Barral Editores, pp. 283-298.

1978 «Componentes Psicológicos-Cognitivos en una Economía Rural Española». A: Ethnica, No. 14: 55-145. Barcelona.

1978 «El Estado, la Etnicidad y el Biculturalismo».

A: Homenaje a Julio Caro Baroja, pp. 327-356. Madrid, Instituto de Investigaciones Sociológicas.

1978 «Acculturation and Urbanization of Immigrants in Barcelona. A Question of Ethnicity or a Question of Class?».

A:Aschenbrenner and Collins, pp. 159-194. The Hague, Mouton Publishers.

1978 «Immigració i Confirmació Etnica a Barcelona».

A: Quaderns d'Alliberament, No. 2-3, pp. 49-70. Barcelona, Edicions de la Magrana.

1978 «El Biculturalismo como Contexto del Bilingüismo».

A: Varios, Bilingüismo, pp. 9-51. Barcelona, Instituto de Ciencias de la Educación, Universidad de Barcelona.

1978 «El Concepto de Etnia y su Aplicación en Etnología».

A: Festschrift to Karl A. Wittfogel, pp. 137-150. The Hague, Mouton Publishers.

1979 «Juan Comas en el Contexto de la Militancia Indigenista».

A: Revista Española de Antropología Americana, vol. IX: 25-34. Madrid.

1979 «Puede Haber una Revolución Comunal en una Sociedad Industrial?».

A: El Ciervo, No. 342-343: 21-22 y 27. Barcelona.

1979 «El Hombre (Entrevista)».

A: Nueva Epoca Naturista, No. 60-61: 26-28. Barcelona.

1979 «Relativismo Cultural».

A: Resurgimiento/Ambito Literario, no. O: 185-200. Barcelona.

1979 «América: Un Largo Proceso de Mestizaje».

A: Historia 16, Extra X, Junio: 119-130. Madrid.

1979 «Notas para una Teoria del Campesinado Andino».

A: Ethnica, No. 15: 29-67. Barcelona.

1979 Recensión a «On a Mediterranean Social Anthropology».

A: Current Anthropology, vol. 20, 2: 405-408. Vancouver, B.C. 
1980 «El Folklore en el Contexto de la Antropología Cultural».

A: La Antropología Americanista en la Actualidad, tom. II: 131-164. Mèxic, Editores Mexicanos Unidos.

ISBN: 968-15-0392-9 (Tom. II)

1980 «Antropología Aplicada: ¿Comunidad o Sistema?».

A: Actas del I Congreso Español de Antropología, Vol. I: 231-282. Barcelona, Universidad de Barcelona.

1980 «Alocución Presidencial».

A: Actas del I Congreso Español de Antropología, vol. I: 3-12. Barcelona, Universidad de Barcelona.

1980 «Erich Fromm: Testigo Crítico de la Actualidad».

A: La Vanguardia, 19 de Marzo, p. 17. Barcelona.

1980 «¿Desencanto Político o Políticos del Desencanto?».

A: El Ciervo, No. 348. Febrero: 30-34. Barcelona.

1980 «El Campesinado Andino como Clase Social».

A: Revista de la Universidad Complutense, vol. XXVIII, No. 117: 391-428. Madrid.

1981 «Comunidades Campesinas y Colonialismo Interno: El Caso Andino». A: Anuario de Estudios Americanos, vol. XXXVIII, pp. 305-352. Sevilla.

1981 «Respuesta a una Cuestión Sobre Folklore».

A: Cultura Tradicional y Folklore, pp. 311-312. Murcia, Editora Regional, S.A.

1981 «El Folklore en el Contexto de la Antropología Cultural».

En Cultura Tradicional y Folklore, pp. 35-68. Murcia, Editorial Regional, S.A.

1981 «La Hispanización del Mestizaje Cultural en América».

A: Quinto Centenario, No. I: 99-141. Madrid.

1981 «Culturas Mesoamericanas Actuales».

A: Razas Humanas, vol. IV: 95-111. Barcelona, Compañía Internacional Editora, S.A.

1981 «Antropología Psicológica».

A: Razas Humanas, vol. I: 241-266. Barcelona, Compañía Internacional Editora, S.A.

1982 «Reflejos Morales en la Literatura Oral: El Caso de los Hispanos de Nuevo México».

A: Ethnica, No. 18, vol. II: 69-92. Barcelona.

1982 «El Campesinado Andino como Terminal Estrutural».

A: Revista de Indias, No. 169-170: 371-392. Madrid.

1982 «Materialismo Cultural en Antropología».

A: Investigación y Ciencia, Julio, pp. 126-127. Nota Crítica a: Marvin Harris, Introducción a la Antropología Cultural. Barcelona.

1982 «Trayectoria de una Vocación y de una Antropología: Autobiografía».

A: Anthropos, No. 10: 4-18. Barcelona, Marzo, Anthropos, Editorial del Hombre. 
1982 «Procesos y Situaciones en la Historia de América».

A: Quinto Centenario, No. 3:199-221. Madrid.

1983 «La mujer expañola en la conquista de América».

A: Comentaris d'Antropologia Cultural, núm. 5:33-57.

Barcelona: Facultat de Geografia i Història, Universitat de Barcelona.

1984 «Final de Etapa».

A: Ethnica, no. 20:3-5. Barcelona.

1984 «Estilos Eticos y Contextos Indígenas en la Conquista de América».

A: Comentaris d'Antropologia Cultural, núm. 6: 7-19.

Barcelona: Facultat de Geografia i Història, Universitat de Barcelona.

1984 «Aproximación a una Antropología de lo Aragonés».

A: Estado Actual de los Estudios Sobre Aragón. Actas de las Quintas Jornadas. pp. 26-37. Zaragoza. Instituto de Ciencias de la Educación.

1984 «Etnocentricity and Bilingualism in Catalonia: The State and Bilingualism».

A: International Journal of the Sociology of Language, 47: 43-57. Berlin, New York, Amsterdam.

1984 «Los Primitivos Actuales».

A: El PAIS, El libro de la Naturaleza, pp. 56-57. Madrid.

1984 «El Desarrollo Democrático Nacional y las Sociedades Indígenas».

A: Caminos de la Democracia en América Latina, pp. 177-193. Madrid, Editorial Pablo Iglesias.

1984 «Ser Catalán».

A: Cambio 16, no. 646: 81. Madrid, 16-23 de abril.

1984 «La Conquista Española ante la Ética India».

A: La ética en la conquista de América (1492-1573). Actas del I Simposio sobre ..., pp. 393-415. Salamanca, Ayuntamiento y Diputación Provincial.

1985 «El Uso del Proverbio en la Antropología Cultural».

A: Actas del II Congreso Iberoamericano de Antropología (1983), pp. 317-332. Las Palmas, Cabildo Insular de Gran Canaria, ICEF.

1985 «Ecologia y Mestizaje».

A: El Mestizaje Americano, pp. 9-19. Madrid, Museo de América.

1985 «Caps i Fàcies a l'Obra d'en Josep Cañas».

A: Fundació Caixa de Pensions (ED.), J. Cañas, 700 Retrats (1922-1983), pp. 7-16. Barcelona, Fundació Caixa de Pensions. ISBN 84-505-2569-1

1985 «Mites i Al-lucinacions».

A: Josep María Fericgla, El Bolet i la Gènesi de les Cultures, pp. 195-215. Barcelona. Editorial Alta-fulla.

1985 «Introducción a Fray Toribio de Benavente».

A: Toribio de Benavente (Motolinia): Historia de las Indias de la Nueva España, pp.

7-45. Madrid. Crònicas de Amèrica, no. 16. ISBN 84-85229-75-4 
1985 «Fecundación Artificial: Entre la Ciencia y el Derecho».

A: El Médico, Marzo, pp. 43-44. Madrid.

1985 «El Concepto de Cultura».

A: Mercedes Fernández-Martorell (dir.), Sobre el Concepto de Cultura, pp. 6180. Barcelona, Ediciones Mitre. ISBN 84-86153-64-6.

1985-86 «Etnologia e Poesia».

A: L'Achenio, Anno IX/X, no. 56/57, pp. 1-2. Palermo, Italia.

1986 «El Estado Nacional Mexica en la Guerra de la Conquista».

A: Actas del Primer Congreso Internacional sobre Hernan Cortés, pp. 325-368.

Salamanca, Universidad de Salamanca.

1986 «Dramatización y Ritual de la Fiesta en Hispanoamérica».

A: José María Díez Borque (comp.), Teatro y Fiesta en el Barroco, pp. 137-152.

Barcelona, Ediciones del Serbal, S.A.

1986 «Una Simfonia Funcional de la Cultura».

A: Quadern de El Pais, 23 de Noviembre, pp. 4-5. Barcelona.

1986 «Etnocidio y Desetnización: El Caso de Perú».

A: Indigenismo, 7, pp. 42-51. Madrid.

1986 «Una Dimensió Naturalista del Racisme».

A: El Mon, Junio, No. 215, pp. 39-41. Barcelona.

1986 «L'Antropología Cultural y les Aportacions que hi va fer Lèvy- Bruhl».

A: Arrel, Febrero, no. 13, pp. 74-76. Barcelona.

1986 «Lecture».

A: Pino Giacopelli, "Amoria”, pp. 11-18. Palermo, Edizioni L'Achenio. Italia.

1986 «La Cultura Indígena en el Pensamiento de las Casas».

A: El Quinto Centenario de Bartolomé de Las Casas, pp. 93-108. Madrid, Ediciones Cultura Hispánica. ISBN 84-7232-388-9

1986 «Etnología y Poesia».

A: Etnostoria. Nuova Serie, Anno 1, 1-2: 25-40. Palermo, Italia.

1987 «Los Indios de Mèxic en la Versión de Cortés».

A: Hernán Cortés y su Tiempo, pp. 475-496.

Mérida, Editora Regional de Extremadura, Junta de Extremadura.

1987 «América: Un largo proceso de mestizaje».

A: Cuadernos Historia 16: 23-31. Madrid.

1987 «El Fenòmen Cultural, Principal Categoria dels Comportaments $\mathrm{Hu}$ mans». A: Arrel, 17, Febrer, pp. 98-104. Barcelona.

1987 «La Muerte en el Contexto de la Cultura».

A: Confluencias, vol. 1. no. 1:30-32. Barcelona.

1987 «Ritual y Dramaturgia: Contexto Antropológico del Teatro».

A: Actes del Congrés International de Teatre a Catalunya, 1985. vol. III: 23-42.

Barcelona, Diputació de Barcelona. 
1987 «Ritual y Dramaturgia: Contexto Antropológico del Teatro. Comedias, Dramas y Tragedias».

A: Homenaje al Dr. José María Basabe. Antropología/Etnología, 5: 165-178. Donostia.

1987 «Sobre Límites y Modos de una Etnopsicología».

A: Anthropologica, 1: 79-91. Barcelona.

1987 «José Alcina en el Contexto de la Antropología Cultural».

A: Anthropos, 68: 30-33. Barcelona.

1987 Recension to Georges E. Marcus (Ed.): «Elites: Ethnographic Issues».

Alburquerque: School of American Research, University of New México Press, 1983, x $+305 \mathrm{pp}$.

A: Journal of Anthropological Research, Vol. 43, No. 1, pp. 93-96. Alburquerque, N.M. (USA)

1988 «Variacions de la Identitat des de l'Antropología».

A: Construint Identitats: Mites i Símbols, pp. 105-120. Barcelona, Publicació Caixa de Pensions, 18.

1988 «Personalidad y Facies de Hispania».

A: Encontre d'Antropología i Diversitat Hispànica, pp. 266-277. Barcelona, Generalitat de Catalunya, Departament de Cultura.

1988 «La Antropologia en Castilla, Hoy: Un Comentario».

A: Luís Díaz (coord.), Aproximación Antropológica a Castilla y León, 446-471.

Barcelona, Editorial Anthropos.

1988 «Antropología Urbana en España».

A: Sistema, no. 82, Enero: 37-65. Madrid.

1988 Recension to Gary Wray McDonogh: «Good Families of Barcelona. A Social History of Power in the Industrial Era».

Princeton, NJ, Princeton University Press, 1986. 278 pp.

A: American Anthropologist, vol. 90, no. 3: 720-721. Washington, D.C.

1989 «Castilla en la Formación Cultural de Hispanoamérica».

A: II Simposio de Historia de la Mancha: Derecho e Instituciones, pp. 165-201.

Valdepeñas, 5-7 de Abril de 1989.

1989 «Contexto y Argumento del Juego Infantil, Extremadura: Diseño Teórico». A: Antropología Cultural en Extremadura, pp. 307-316. Mérida, Asamblea de Extremadura.

1989 «Antropologia, Folklore e Identidad Cultural».

A: Antropología Cultural en Extremadura pp. 15-33. Mérida, Asamblea de Extremadura.

1989 «Los Indios de Mèxic en la Sociedad Nacional Mexicana».

A: Situació Actual de la Població Indígena a l'América Llatina, pp. 3-31. Barcelona, Ajuntament de Barcelona, Museu Etnológic. 
1989 «Metáfora y Dialéctica de la Cruz en Mesoamérica».

A: Homenaje Andaluz a Julian Pitt-Rivers, El Folklore Andaluz, Segunda Epoca, 4: 139-163. Sevilla. Fundación Machado.

1990 «Poblamiento y Urbanización Hispánicos del Nuevo México».

A: Revista Española de Estudios Norteamericanos, número 3: 85-103. Universidad de Alcalá de Henares. Alcalá de Henares.

1990 «Indígenas, Memorias Etnicas y Sociedades Abiertas. Perspectivas Comparadas».

A: José Alcina Franch (comp.), Indianismo e indigenismo, pp. 102-131. Madrid, Alianza Editorial.

1991 «Los Indios de Mèxic en la Sociedad Nacional Mexicana».

A: Cuadernos Hispoamericanos, Los Complementarios/7-8. Julio, pp. 129-154. Madrid.

1992 «El Indio Americano».

A: El Ciervo, 497-498, Agosto/Septiembre, pp. 12-13. Barcelona.

1992 «Aculturación y Resistencia en Mesoamérica: Siglo xvI».

A: Congreso de Historia del Descubrimiento, Tom. I: 285-342. Madrid, Real Academia de la Historia, Confederación Española de Cajas de Ahorro.

1992 «Reflexions sobre el Descobriment: Els Indis d'Amèrica i la Conquesta Espanyola».

A: Set Dies, Idees, El Observador, 11-X-1992, pp. 6-7. Barcelona.

1992 «I Meticci Del Nuovo Mondo».

A: Uomini e Culture, pp. 207-212. Venezia, Edizioni Colombo.

1992 «La Hermosa Diversidad y los Intelectuales».

A: Comité de Expertos, En el Umbral del Tercer Milenio, pp. 165-168. Sevilla, Comité de Expertos, Oficina del Comisario General de la Exposición Universal, Sevilla 1992.

1992 «L'Exili Català als Països Americans: Una Perspectiva Antropològica».

A: IV Jornades d'Estudis Catalano-Americans, pp. 227-242. Barcelona, Generalitat de Catalunya, Comissió Amèrica i Catalunya, 1992.

1992 «De Antropología Esquimal y sobre Ramón H. de Larramendi».

A: Ramón Hernando de Larramendi, Los Esquimales, pp.11-14. Madrid, Editorial Mapfre.

1992 «Historia y Cultura de los Mexicas».

A: El Imperio Azteca. "Relatos del Nuevo Mundo", pp. 4-5 \& 22 pp. Barcelona, Planeta-Agostini, Quinto Centenario.

1992 «Situación Actual de los Indígenas y Derechos Humanos».

A: Raíces Ibéricas del Continente Americano, pp. 116-124. Y: pp. 131, 134, 135, 137, 139. Madrid, Colegio Mayor Zurbarán, IV Simposio sobre el V Centenario del Descubrimiento de América. 
1992 Presentació

A: Prócoro Hernández, Els Catalans i el món indígena americà, pp. 9-11. Barcelona: Generalitat de Catalunya, Comissió América i Catalunya, 1992.

1992 «Els Catalans a L'Amèrica Contemporània».

A: Les Amèriques i Catalunya, pp. 337-351. Barcelona, Generalitat de Catalunya, Departament de la Presidència, Comissió Amèrica i Catalunya, 1992.

1992 «'ús social de la llengua catalana».

A: Dinàmica social i factors intervinents en l'extensió de l'ús social del català, Vol. 3: 9-17. Barcelona, Generalitat de Catalunya, Departament de Cultura.

1992 «Josep Cañas: Més que sempre».

A: Catàleg de l'Exposició d'Escultura d'en Josep Cañas, pp. 44-51.

Barcelona, Generalitat de Catalunya, Departament de Cultura.

1993 «Metáforas y Transformaciones de la Identidad en Mesoamérica: Siglo xvI». A: Anales de Antropología 30: 183-228. Mèxic, Instituto de Investigaciones Antropológicas, UNAM.

1993 «La Influencia de las Universidades Indianas en el Contexto de las Sociedades Indígenas».

A: Actas del Congreso Internacional de Universidades, pp. 261-290. Madrid, Editorial Complutense.

1993 «Antropología Cultural».

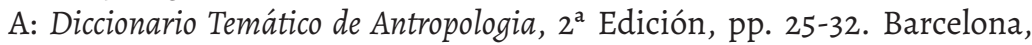
Editorial Boixareu Universitaria. Angel Aguirre (ed.).

1993 «Mayas y Españoles: La Visión del Otro».

A: Perspectivas Antropológicas en el Mundo Maya, pp. 15-30. Edición de Maria Josefa Iglesias Ponce de León y Francesc Ligorred Perramon. Madrid, Publicaciones de la S.E.E.M., 2.

1993 «Motolinia: Una visión del Mundo Indio de su Tiempo».

A: Fondo Manuscrito Americano de la Biblioteca de San Lorenzo del Escorial, Monografias Históricas 1: 149-195. San Lorenzo de El Escorial.

También A: Anuario Jurídico y Escurialense, Epoca II, Número XXV: 561-607. San Lorenzo de El Escorial, Real Colegio Universitario Maria Cristina.

1993 «La Història de l'Antropologia, ¿Branca o Tronc de l'Antropologia?»

A: Aportacions a la Història de l'Antropologia Catalana i Hispànica, pp. 1-42.

Barcelona, Generalitat de Catalunya, Departament de Cultura.

1994 «Elementos para una Teoría del Trabajo en la Améria Indígena».

A: Claudio Esteva-Fabregat (Coordinador), Sistemas de Trabajo en la América Indígena, pp. 9-81. Quito, Ecuador, Ediciones Abya-Yala.

1994 «Introducción»

Sistemas de Trabajo en la América Indígena.

A: Claudio Esteva-Fabregat (coord.), Sistemas de Trabajo en la América Indígena, pp. 7-8. Quito, Ecuador, Ediciones Abya-Yala. 
1994 «Identidades no Estatales en la Europa de los Pueblos». Dialécticas: Pueblos, Naciones y Estados.

A: José Luis Abellán (coord.), El Reto Europeo, pp. 41-54. Madrid, Editorial Trotta \& Asociación de Hispanismo Filosófico.

1994 «Dos Móns del Discurs Evolutiu des de l’Antropologia, la Biologia i la Cultura».

A: Revista d'Etnologia de Catalunya, pp. 62-77. Barcelona.

1994 «El Modo Social del Parentesco en la Cultura Fang».

A: Ensayos en honor a Carmelo Lisón, pp. 93-117. Madrid, Centro de Investigaciones Sociológicas.

1994 «Antropologia, Per a Què?»

J. Vilà i Valentí, Les Relacions entre Ciència i Societat a Catalunya a la fi del segle xx, pp. 159-223. Barcelona, Fundació Catalana per a la Recerca. Collecció Ciència i Societat. ISBN 84-604-9826-3

1994 «Pensamiento y Política en la Historia de España: Una Reflexión».

A: Sistema, 120, pp. 73-81. Mayo 1994. Madrid.

1994 «El Mundo Folk en los Estudios Antropológicos».

A: Actas do Simposio Internacional de Antropología.

In Memoriam Fermin Bouza-Brey.

Santiago de Compostela-Ponteareas, 10-12 Septiembre, 1992. Conselho da Cultura Galega, pp. 125-149.

1995 «Opinión sobre "Indice" y J. Fernández Figueroa».

A: Indice: Panorama de la Cultura Contemporánea. El sentido Liberal de la Ambigüedad, p. 47. Cáceres, Ediciones, Revista de Extremadura.

1996 «Ethnology, Folk Culture and Spanish Anthropology».

A: Ethnologia Europaea 26:111-122.

1996 «Entrevista con Claudio Esteva-Fabregat».

Por: Jordi Colobrans, Ángel Martinez y Joan Prat.

A: Prat, Joan \& Martinez, Ángel (eds.). Ensayos de Antropologia Cultural. Homenaje a Claudio Esteva-Fabregat, pp. 15-25. Barcelona, Ariel Antropología.

ISBN: 84-344-2204-2

1996 «Malinowski Award Lecture. Being an Anthropologist: A reflexion».

A: Human Organization 55, 1: 117-124. Dallas, USA.

1997 «Pere Bosch-Gimpera i els Estudis de Prehistòria a Mèxic».

A: V Jornades d'Estudis Catalano-Americans, Maig 1993, pp. 99-107.

Barcelona, Generalitat de Catalunya, Departament de la Presidència.

1997 «Dialèctiques de la Cooperació a les Societats Humanes».

A: Revista d'Etnologia de Catalunya, 11: 8-19. Barcelona, Centre de Promoció de la Cultura Popular i Tradicional Catalana. 
1997 «Etnicidad Indígena y Globalización en América. Una Reflexión».

A: M. Gutiérrez Estevez (comp.), Identidades Étnicas, pp. 147-178. Madrid, Casa de América de Madrid. Col. Diálogos Amerindios vol. I.

1997 «El Context del Científic és la Cultura».

A: Humanisme i Responsabilitat dels Científics. Seminari Permanent, La Responsabilitat Social dels Científics, nº 4:49-63. Barcelona, Fundació Catalana per a la Recerca.

1997 «La Cuestión Nacional Catalana en la España Contemporànea»

A: Alteridades, Año 7, 14:35-53. Mèxic, D.F., Universidad Autónoma Metropolitana.

1997 «Nacionalismos de Estado y Nacionalismos de Liberación y Recursos Ideológicos del Racismo».

A: VI Jornadas Lascasianas. La problemática del racismo en los umbrales del siglo XxI,pp. 337-393. Mèxic, D.F., Cuardenos del Instituto de Investigaciones Jurídicas, UNAM.

1998 «Sobre el Origen Indiano de la Antropología Cultural».

A: Etnostoria, I-2: 23-66. Palermo, Italia.

1998 «Mons i entorns de la Universitat. Una reflexió».

A: Eduard Bonet i Josep A. Plana (comp.), Responsabilitati Canvi, pp. 65-97.

Barcelona, Fundació Catalana per a la Recerca. Debats 1

1998 «QQuina valoració personal fa de l'aplicació de l'Estatut en aquests vint anys?» En: Avui, Barcelona, 11 de Setembre.

1998 «Procesos de Aculturación y Transculturación».

A: David Sobrevilla) (ed.), Filosofia de la Cultura, pp. 145-162. Madrid, Enciclopedia Iberoamericana de Filosofía, CSIC, Editorial Trotta.

1998 «Le civiltà indigene delle Americhe. Aree culturali».

En colaboración con Francesco Paolo Campione, Roque de Barros Laraia y Juan Ossio.

A: Etnostoria, Saggi 3:39-125. Palermo.

1998 «Quijotismos en las Culturas Hispanoamericanas».

A: Don Quijote y América, pp. 21-112. Ciudad Real, Universidad de Castilla la Mancha, Servicio de Publicaciones.

1999 «Códices Mexicanos y Textos Etnográficos».

A: Thule, 6-7, Aprile-Ottobre: 153-189. Perugia, Centro Studi Americanistici "Circolo Amerindiano"

1999 «Pròleg».

A: Diccionari Català-Xinès. Barcelona, Enciclopèdia Catalana.

1999 «Sobre Modos de Identidad en la Cultura».

A: Jacinto Choza y Octavi Piulats (Eds.), Identidad humana y fin del milenio.

Thémata, Revista de Filosofía, 23:31-68. Sevilla 
1999 «Encuesta: Situación de la Antropología en España».

A: DEMOS, Separata, pp. 81-82. Dresden, Alemania.

1999 «Un Recull de Poesia. Pròleg».

A: Dolors Thomas i Fabregat, Espurnes Poètiques, pp. 11-18. Cubelles, Ajuntament de Cubelles, i Dolors Thomas i Fabregat.

2000 «El Bosque Hostil o la Dialéctica del Nacionalismo».

A: José Alcina/Marisa Calés (eds.), Hacia una ideología para el siglo XxI, pp. 59-101. Madrid, Akal Ediciones.

2000 «Los Derechos Humanos, una Forma de la Dialéctica».

A: Rafael Pérez Taylor et alii, Aprendery Comprender la Antropología, pp. 87-120.

Mèxic, Compañía Editorial Continental.

2000 «Pròleg: L'Art de Cañas, una Forma d'Antropologia».

A: Josep Cañas. Mèxic, Els meus anys amb els indígenes. pp. XVII-LXXIII.

Barcelona, Editorial Viena/Art.

2001 «Memoria de un Tiempo de la Antropología Mexicana».

A: Barba, Rodriguez, Berruecos y Barjau (eds.): Antropología e Historia

Mexicanas. Homenaje al maestro Fernando Cámara Barbachano, pp. 63-77.

Mèxic, Instituto Nacional de Antropología e Historia.

2002 «Societat de la Informació o Societat de la Innovació?»

A: Eduard Bonet i Jordi Mas (dir.), Reptes i Problemes. L'Impacte de la Societat de la Informació. pp. 95-144. Publicació en homenatge al Dr. Enric Casassas i Simó. Barcelona, Fundació Catalana per a la Recerca. Debats 2.

2002 «Testimonio y memoria de Ignacio H. de Larramendi».

A: Mecenazgo cultural de Ignacio Hernando de Larramendi y Montiano,

pp. 118-120. Madrid, Fundación Mapfre Tavera.

2002 «Indianismo y Biculturalismo en Chiapas».

A: Louis Cardaillac \& Angélica Peregrina (coords.), pp. 221-268.

Ensayos en Homenaje a José María Muriá.

Zapopan, Mèxic, El Colegio de Jalisco. ISBN: 968-6255-76-1

2002 «Sobre la Historia de la Antropología en Cataluña».

Prólogo a: Jerónimo Bouza, El hombre como problema, pp. 7-39. Barcelona, Ediciones del Serbal.

2003 «Memoria de una Antropología de Campo: Chinchero».

A: Revista Española de Antropología Americana, Volumen Extraordinario, pp. 363-385. Madrid, Universidad Complutense. ISSN 0556-6533

2003 «El Arte de Cañas, una Forma de Antropología».

A: Josep Cañas: Mèxic, mis años con los indígenas, pp. XVII-LXXVII.

Zapopan, Jalisco, Mèxic, El Colegio de Jalisco; i a Barcelona, Editorial VIENA/ART, Edición en catalán, 2000. 
2003 Recensión a Francisco Lizcano Fernández: «Desarrollo socioeconómico de América Central en la segunda mitad del siglo xx».

A: Revista del Ateneo de Madrid. Madrid; y a Toluca, Mèxic, Universidad Autónoma del Estado de Mèxic, 2000.

2004 «Formes de la diversitat en la cultura: L'argument de la diferenciació».

A: Albert Bastardas i Boada (ed.), Diversitats, llengües, espècies i ecologies, pp. 54-132. Barcelona, Grup Editorial 62 - Editorial Empúries. ISBN. 84-9787040-9.

2004 «Otros Rumbos en la Antropología Social».

Academia Mexicana de Ciencias Antropológicas, A.C. Memoria número 1: 70-82. CONACULTA-INAH, Mèxic, D.F., 2002-2004.

2004 «Cultura Transversal»

Recensión a Mandawuy Yunupingu y Lowitja, Elders, Wisdom from Australia's Indigenous Leaders. O'Donoghue, Cambridge University Press. 2003. A: Scientific American, Año 2, $n^{\circ}$ 24, p. 92 . Barcelona.

2005 «Representaciones y Especies del Poder».

A: Rafael Pérez-Taylor (ed.), Las Expresiones del Poder. IV Coloquio Paul Kirchhoff: Homenaje al Doctor Claudio Esteva Fabregat, pp. 19-37. Mèxic, Universidad Nacional Autónoma de México, Instituto de Investigaciones Antropológicas. ISBN. 970-32-2177-7.

2005 «Epílogo. Holismos Etnográficos y Focos Asociativos».

A: Rafael Pérez-Taylor (ed.), Las Expresiones del Poder. IV Coloquio Paul Kirchhoff: Homenaje al Doctor Claudio Esteva Fabregat, pp. 375-445. Mèxic, Universidad Nacional Autónoma de México, Instituto de Investigaciones Antropológicas. ISBN. 970-32-2177-7.

2005 «Teoría de un Destino Manifiesto»

Recensión a Patrick Brantlinger, Dark Vanishing, Discourse on the Extintion of Primitive Races, Ithaca \& London, Cornell University Press, 2003.

En. Scientific American. Octubre. Barcelona. España, p. 95.

2006 «Significados Antropológicos del Arte».

A: Nueva Historia Universal del Arte, Tom. I: Arte y Civilizaciones, pp. 15-45. Barcelona, Lunwerg Editores. ISBN: 84-9785-308-3.

2008 «Etnología e Poesia».

A: Piero Di Giovanni, La Continuità Possible, Volume in onnore di Aurelio Rigoli, pp. 265-272. Palermo, Italia, Edizioni Fotograf. ISBN 978-88-95272-29-0.

2008 «Realidad Vital y Representación Virtual. Anatomía de una Reificación. Una Reflexión».

A: Andrés Fábregas, Mario Alberto Nájera y José Francisco Román, (coord.), Regiones y Esencias. Estudios sobre la Gran Chichimeca, pp. 13-30.

Mèxic, Ediciones Presente y Futuro. ISBN 978-607-00-0510-7 
2008 «Acompañamientos a una teoría de la complejidad».

A: Desacatos, 28: 101-134. Mèxic, CIESAS. ISSN 1405-9274

2008 «Elements per a una Història de l'Antropologia Catalana».

A: Lluís Calvo (ed.), Construint Ciència des de la Catalunya Contemporània, pp. 31-75. Barcelona, Publicacions de la Residència d'Investigadors, Consell Superior d'Investigacions Científiques-Generalitat de Catalunya.

ISBN: 978-84-931588-3-5.

2009 «Una reflexión temática sobre etnicidad y representaciones étnicas».

Prólogo al libro de José de Jesús Torres Contreras, Relaciones de frontera entre los huicholes y sus vecinos mestizos. Páginas 13-53. Zapopan, Jalisco. El Colegio de Jalisco.

2009 «Agradecimientos»

A: Claudio Esteva-Fabregat. Maestro Emérito, pp. 9-14. Zapopan, Jalisco, Mèxic. Presencias, El Colegio de Jalisco. ISBN 978-607-7770-00-8

2009 «Ser Antropólogo Hoy»

A: Claudio Esteva-Fabregat. Maestro Emérito, pp. 57-101. Zapopan, Jalisco, Mèxic. Presencias, El Colegio de Jalisco. ISBN 978-607-7770-00-8

2009 «Gonzalo Aguirre Beltrán: Semblanza corta para una historia larga». Contrapunto, Vol.4, Enero-Abril, número 10:63-81. Xalapa, Veracruz, Mèxic. $<$ https://www.academia.edu/2377584/Gonzalo_Aguirre_Beltr\%C3\%Ain_ Semblanza_corta_para_una_historia_larga>

2009 «Exilio y desexilio: Experiencia de una Antropología. México-Madrid-Barcelona.»

Revista electrónica de Geografia y Ciencias Sociales, Scripta Nova, Vol. XIII, 25 de Mayo, 2009, número 291: 1-36. Barcelona.

<http://www.ub.es/geocrit/sn/sn-291.htm>

2010 «Esbozos para una teoría de la razón médica. Estudio Introductorio».

A: Raúl González Enríquez, Notas para la interpretación del pensamiento mágico, pp. 14-102. Veracruz, Mèxic, Editora de Gobierno del Estado de Veracruz. ISBN 978-607-7527-30-5

2010 «Antropología y Consciencia Nacional Mexicana».

A: Claudio Esteva-Fabregat (coord.), Antropología y Consciencia Nacional Mexicana, pp. 15-85. Zapopan, Jal. Mèxic, El Colegio de Jalisco.

ISBN 978-607-7770-11-4

2010 «Presentación».

A: Claudio Esteva-Fabregat (coord), Antropología y Consciencia Nacional Mexicana, pp. 9-13. Zapopan, Jal. Mèxic, El Colegio de Jalisco.

ISBN 978-607-7770-11-4 
2010 «Juan Rulfo: Creación literaria y percepción antropológica». Ámbitos de una Antropología literaria.»

A: Jorge Zepeda (coord.), Nuevos Indicios sobre Juan Rulfo, pp. 181-218. Mèxic, Fundación Juan Rulfo, Juan Pablos Editor.ISBN 10: 6077700657

2010 «Sobre el concepte de maduresa».

Revista de la Universitat de Barcelona, Any XIV, Febrer, n 50: 17-19. Barcelona, Universitat de Barcelona

2010 «Sobre el modo de percepción paya de la otredad gitana. Apuntes y memorias de un tiempo infantil».

Prólogo al libro de David Lagunas, Segregar, producir, contestar. Una etnografia con gitanos andaluces de La Mina, pp.9-17. Madrid, Ed. Entimema. ISBN 978-84-8198-808-6

2011 «Regionalismo y Antropología en la obra de Andrés Fábregas». Recensión a Andrés Fábregas, Configuraciones Regionales Mexicanas. A: OPUS, Sociedad. Artes. Cultura. Año 1, núm. 1., mayo-agosto, pp. 74-78.

2012 «Repensar lo Múltiple y lo Complejo en la Gran Chichimeca».

A: Historia, Antropología y Fuentes Orales 47-48, pp. 41-65. Barcelona, Año $2012,5^{\mathrm{a}}$. Época.

2012 «Panorama y repaso de la antropología contemporánea. Una reflexión». A: Claudi Esteva, Josep Ligorred y María Isabel Campos (coord.), Miradas Catalanas en la Antropología Mexicana, pp. 13-71.Mèxic D.F.- Mérida, Instituto Nacional de Antropología e Historia - Escuela Nacional de Antropología e Historia - Casal Catalá de la Península de Yucatán.

ISBN 978-607-484-264-7

2012 «Antropología y consciencia nacional mexicana».

A: Claudi Esteva, Josep Ligorred y María Isabel Campos (coord.), Miradas Catalanas en la Antropología Mexicana, pp. 185-253. Mèxic D.F.- Mérida, Instituto Nacional de Antropología e Historia - Escuela Nacional de Antropología e Historia-Casal Catalá de la Península de Yucatán.

ISBN 978-607-484-264-7

2012 «Panorama de la Gran Chichimeca»

A: Andrés Fábregas, Mario Alberto Nájera y Cándido González (coord.), Transversalidad y paisajes culturales, pp. 33-46. Guadajalara, Jal., Mèxic, Seminario Permanente de Estudios de la Gran Chichimeca.

ISBN 978-607-7770-59-6

2012 «Presentació Joan Prat i Carós»

A: Jesús Contreras, Joan J. Pujadas i Jordi Roca Girona (eds.), Pels camins de l'Etnologia: un homenatge a Joan Prat. Tarragona, España, Universitat Rovira i Virgili. ISBN 978-84-8424-219-2 
2013 «El mestizaje en América».

Republicat como "Artícle Clássic"

A: Revista Tiempo y Espacio de la Universidad del Bío-Bío, Chile.

Revista Indexada en Latindex.

2015 «A título de testimonio».

A: Francisco Ferrándiz, Juan Antonio Flores, María García Alonso, Julián López García y Pedro Pitarch (eds.), Manuel Gutiérrez. Maestro de Etnógrafos (Americanista), pp. 31-35. Iberoamericana-Vervuert, Madrid-Frankfurt. ISBN 978-84-848-9916-7

2016 «Perfiles de una Antropología Etnográfica».

A: Claudio Esteva-Fabregat (coord.), Ortodoxias y Heterodoxias en la Antropología Mexicana, pp. 13-50. El Colegio de Jalisco, Zapopan, Jal. Mèxic.

ISBN 978-607-8350-54-4

2016 «Presentación».

A: Claudio Esteva-Fabregat (coord.), Ortodoxias y Heterodoxias en la Antropología Mexicana, pp. 7-11. El Colegio de Jalisco, Zapopan, Jal. Mèxic.

ISBN 978-607-8350-54-4

2016 Los capuchinos catalanes y la europeización colonial de los indigenas de Trinidady Guayana

Inèdit

2017 «Auge Misionero y declive chichimeca: una reflexión».

A: Andrés Fágrebas Puis, Mario Alberto Nájera Espinoza, Armando Vázquez-Ramos (coords.), Territorio e imaginarios en la Gran Chichimeca, pp. 83-101. Guadajalara, Jal., Mèxic, Seminario Permanente de Estudios de la Gran Chichimeca. ISBN 978-607-8562-03-9.

Voluntarios y misioneros catalanes franciscanos en la conquista y formación de la Alta California.

Inacabat

Memoria de un tiempo de la antropología mexicana:la ENAH (1940-1960). Inacabat 